\title{
IAMJ
}

INTERNATIONAL

AYURVEDIC

MEDICAL JOURNAL

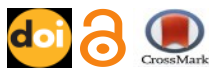

Review Article

ISSN: 23205091

Impact Factor: 5.344

\section{STUDY OF PERICARDIUM WITH SPECIAL REFERENCE TO 'KALA SHARIR’}

\author{
Rahul S. Suryavanshi ${ }^{1}$, Yogesh T. Kotangale ${ }^{2}$, Sumedha Y. Kotangale ${ }^{3}$ \\ ${ }^{1}$ Associate Professor, Dept. of RachanaSharir, \\ ${ }^{2}$ Associate Professor, Dept. of Kayachikitsa, \\ ${ }^{3}$ Assistant Professor, Dept. of Shalakyatantra, \\ MAM s Sumatibhai Shah Ayurved Mahavidyalaya, Hadapsar, Pune, Maharashtra, India
}

Email:drytk@yahoo.com

\section{https://doi.org/10.46607/iamj0807272020}

(Published online: July 2020)

Open Access

(C) International Ayurvedic Medical Journal, India 2020

Article Received: 07/07/2020 - Peer Reviewed: 10/07/2020 - Accepted for Publication: 10/07/2020

Check for updates

\section{ABSTRACT}

During graduation when we study Rachana Sharir in first year, lot of textbooks of Rachana Sharir mention 'Pericardium' as a 'Vishesh Kala'. But when we study the Sharir Sthana of Sushrut Samhita, Charak Samhita, there is not any word related to this 'Vishesh Kala'. Also, when we study Sharir Sthana of Charak or Sushrut, whether they mention the Pericardium or not, if mentioned in which topic they mentioned. And what is the term used for pericardium in Ayurveda. Is it 'Hridayacchadit Kala' or 'Hridayavaran'. Hridayarnava is mentioned in Charak Samhita as a Kalpa which are very useful to protect heart from poisons (Visha Chikitsa). To know that, when Ayurvedic and modern literature study and dissection was done it was observed that there are only Sevan Kala. Charak, Sushrut, Vagbhat or no other Acharya mention Vishesh Kala. Kala is a gross organ. The Kala are the nervous, intestinal, and mucous membranes, meaning they belong to the Fibrous, Serous, or Mucous Membrane. Along with the Dharan of Kala, there are other functions that can vary according to the Kala, that is, Kala has special qualities. Charak, Sushruta, Vagbhata have not described any special Kala. Pericardium is very similar to Mansadhara Kala, so it seems reasonable to include it in Mansadhara Kala.

Keywords: Pericardium, Vishesh Kala, Kala Sharir 


\section{INTRODUCTION}

According to Sushrutacharya, if research is done on dubious things and combining it with the latest medical sciences, its dubiousness will be removed and the differences of opinion about such things in Ayurveda will reduce and it will help to reach consensus the controversial things. One of such dubious things is 'KalaSharir'(1). There are differences of opinion among many Ayurveda experts about the exact nature of Kala. Additionally, while dissecting the cadaver, we find the Pericardium covering the heart, but if you try to find its references in Ayurveda, it is found nowhere or is referred to as 'special Kala'. No special

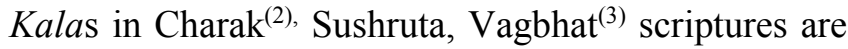
mentioned. The pericardium is a macro structure that is visible to the naked eye, which can be separated into two layers and covers a very important organ like the heart.

In Ayurveda, there are many descriptions about the heart. The heart is said to be the abode of mind, on and contemplation. The treatment of heart disease is also described ${ }^{(4)}$. Most of the scriptures refer to this structure on the heart as Pericardium and also describe its transactional body e. g. Pericarditis, pericardial effusion. Sushruta describes the structure of the skin, which is even more subtle than the pericardium, Considering the structural and functional importance of this overlapping structure, it seems more time appropriate, without interfering with Ayurvedic principles $^{(5)}$. Therefore, in selecting this structure for special studies, this study can help to make this structure clearer and more precise.

Aim: Study of pericardium with special reference to Kala Sharir

\section{Objectives:}

1. Review of literature regarding Kala Sharir

2. Study of Pericardium in anatomical view.

\section{Material \& Methods}

The study has been conducted in two phases:

a) Conceptual study:

A detail Ayurveda literature regarding: 1) Kala Sharir and 2) Pericardium from Samhitas and their commentaries as well as other contemporary writing has been reviewed or studied.
A detail Modern literature regarding: 1) Pericardium anatomy and 2) Clinical anatomy of Pericardium.

\section{b) Cadaveric dissection of Pericardium.}

\section{DISCUSSION}

It has so far given a general description of the $\mathrm{Kal}$ as. Kala has many meanings in Sanskrit ${ }^{(6)}$. There are 3 main meanings of Kala in Ayurveda.

1.Thin membrane / Anga Pratyang,

2.Vikar

3.Qualities (Guna).

1)There is no need to consider disorders in this because these disorders are not of the body, they are of nature and the section in Ayurveda in which the word Kala has been used has nothing to do with physical disorders. For this, Kala itself means disorder.

2) Another meaning of Kala is body parts. Kala is mentioned in the chapter by Sushruta called Sharirsankhya Vyakarana ${ }^{(7)}$

Based on the tradition in which Kala is mentioned here, it can be said that Kala is a bodily organ just like the bodily organs like liver, spleen, heart etc. Which can be dissected after dissection like other body parts and its number can also be fixed.

It is clear that Kala is a perceptual organ and its calculation can be ascertained. The following sutras are found about the thickness of Kala, '- SvalpavatKalasanjya:, both the words' short' and 'short' are used to describe a small amount of matter in the form of atomic matter, not for the main substance. There has been a relative effort for the word short or short for Kala. Because the Kala is thinner and smaller than other organs, it is less or less mutilated. Dalhnacharya uses the unmanifest word for Kala. This term is found in the following Shloka in the verse 'Yathasaar: kashteshu'.

From this it is clear that the invisibility of Kala is due to its subtlety, not to its subtlety. Due to the intricacies of Kala in life, its invisibility is expressed through its work. This is the result of Dalhanachar$y a$ 's promise. It has nothing to do with the subtlety of Kala. Haranchandra's words are about the Mansadhara Kala are not normal. Besides, that verse 
does not mean that it is not about taste. If you think about it and try to find it, it can be about visibility.

3) Kala also has a meaning of virtue. From this point of view, 'dhatvashyantaramaryada ${ }^{\prime(8)}$ means the virtue of producing one Dhatu from another and from one Aashaya to another. But points cannot be obtained without any basis.

Chakrapanidatta has considered the difference between the two ${ }^{(9)}$. If Kala means virtue, then according to the above principle, the Kala of producing from one Dhatu to another Dhatu is the realization of the bodily organ which has the quality; in short, the question arises as to whether Kala is a virtue or a nonvirtue. In Nirguna there is only the realization of Dharana, and in Saguna there is the realization of all the special works of Kala besides Dharana.

Pittadhara Kala- This is used to cover the small intestine. Modern scholars say that it has the power to stimulate and hold the digestive juices of the pancreas and liver, to absorb the digestive tract and to produce digestive juices called succusentericus. With regard to the production of Antras, it is doubtful that this juice originates from a special gland of the intestine (Crypts of Liberkuhn). In this connection, the answer may be that these glands belong to the Kala or the interface of both is formed from a kind of cell. Contained within or belonging to the mucous membrane are the following structures-Circular folds, Villi, Intestinal glands etc. The word belonging is important in Gray's Anatomy ${ }^{(10)}$. A basement membrane, supporting a single layer of epithelial cells, which throughout the intestine are columnar in character. The Gland's walls are thin, consisting of a basement membrane lined by columnar epithelium.

Spleen is specially mentioned in Kala. In Ayurveda, hematopoiesis is considered to be related to the liver and spleen. It is not impossible that the authors intend to indicate some relation of hematopoiesis, when referring to hepatic spleen in hematopoiesis. Modern microbiology has shown that the lining of the capillaries and blood vessels of the liver and spleen (which is included in the blood vessels) is made up of a special type of cell called aretino endothelial cell.
Other R.E. cells are sessile, for example the stellate cells of Kupffer, which constitute on imperfect lining for the hepatic capillaries. Other sessile components of the reticulo - endothelial systems are the endothelium of the lymph sinuses and splenic sinuses etc. Halliburton's Physiology. Hematopoiesis is one of the many functions of this cell. During pregnancy and for some time after birth, the liver and spleen cells work. In the fetus the liver and spleen take part in blood formation, but in the adult, it is confined to the red bone marrow - Halliburton's Physiology.

The functions of large intestine are mechanical, absorptive and excretory. The mechanical functions of large intestine comprise the storage of faeces, and their evacuation at due intervals. The large intestine absorbs chiefly water. From the above description, it is clear that Kala is not just a quality, not a Dhatu formation cell, but a membrane with special functions. Appearance and shape: In order to gain an understanding of the chapter and the order in which the Kalas are considered. It is important to pay attention to it. An example of this is given by Prasaad. Just like when describing a mansion, its types are described, then its partition walls.

There are descriptions of various rooms like halls, bathrooms, warehouses, etc. made up of it, as well as in the chapters on conception and body grammar, the body prasaad is described. The location of the type first describes the skin, the location of the interstitial Kalas, and then the location of the interplanetary. With this example in mind, it is not difficult to understand the meaning of the term 'Dhatvashayantarmaryada'. In short, Kala is an organ of the body that covers the skin, but the skin is outside, the Kala is therefore implicit inside. The skin is thick and broad (all over the body), the Kala is thin and light (covering one limb). According to modern Western definitions, Kala is in the form of Membrane, Fascia, Septa. Considering its structure, it can be Fibrous Membrane, Serous Membrane and Mucous Membrane.

According to Sushruta, in the verse of $4 / 6$, all the seven Kalas are translated in the following way ${ }^{(11)}$. 1. Mansadhara Kala- Deep Fascia, Inter- 
muscular Septa. 2.RaktadharaKala - Endothelial lining of the blood vessels and sinuses in the liver and spleen. 3. Medodhara Kala- Omentum, Deep Fascia 4. Schleshmadhara Kala- Synovial Membrane 5. Purishadhara Kala - Mucus membrane of the large intestine (Colon \& Rectum) 6. Pittadhara Kala - Mucus Membrane of the small intestine 7. Shukradhara Kala - Mucus Membrane of the vasiculae seminals Vas -deferentiate etc.-

The number and definition of Kala is described in the fourth sutra of the fourth chapter of Sushruta Sharira sthana. In the fifth verse, the special nature of Kala is explained. The nature of Kala is described in the sixth verse.

Khalu: This preposition is used for definite or regular meaning. Its mention means that their number is seven not only because of 7 Twacha (Skin layers). In fact, their number is 7 . Not less than this is more than this.

Ashtanga Sangraha Tikakara Indu ${ }^{(12)}$ stated that Dhatu and Aashay are considered as separate Dhatus. Although there are some differences in the way it is interpreted, there is no significant difference in the definition of Kala. Both mean that Kala is an appendage of the body that distinguishes between the Dhatus and the Aashaya of the body. However, he meant all Dhatus. Although Mans conveys the essence of Mans, since it represents wood, it means cover. That is, it has been used as an alternative to Kala. The fifth person in a nutshell implies that, just as the essence of a tree is that the holder has to remove the top wood or cover to see the nutrients.

Similarly, in order to see the body's nutrients, the covering has to be removed and after removal, it appears. Of course, the body has all the Dhatu covering and this covering is called Kala. The three words used in these people, pratichchanna, santata and veshtit, after separation, show the same meaning and that is creation. The mucous membrane, which is the lining of the Kalas, is made up of fibrous, the serous membranes and the mucus. But it is not necessary that these three be present in every Kala. Some Kalas are formed by mucus, some by fibrous, some by serous and some by their mixture. According to modern def- initions, the neural crest is called Fibrous, the placenta is called Serous and the placenta is called Mucous. In short, the various Kalas in the body are fibrous, serous or mucous. Let us now consider the 'pericardium. In the description of the pericardium we see that it covers the heart in the middle mediastinum and is a fibroserous sac. According to the Sushruta, Mediastenum is also a void or space, so it can be called Aashay.

According to Bhavmishra, in Ura, Kapha is situated means Sthana. ${ }^{(13)}$ Below the Shelshmashaya is the stomach. Scientists also say that Shelshmashaya is in the thorax and the Kapha resides in the stomach, heart, throat, head and joints of the human being respectively.

From this it is said that Mediastinum is the Shelshmashaya and we call the muscles of the heart which are the MansDhatus. Gray also states that the Pericardium is a Fibroserous Sac. Gray states that there are two main layers of Fibrous and Serous in the Pericardium. The clay that remains in the middle of the Dhatu and the material, the clay that matures by its own heat and is covered by the lining of the muscles, mucus and spleen, or is left over from the essence of the Dhatu and does not form and advance juice is called Kala. According to these people, the formation of Mycardium (Heart Muscles) is the formation of the splanchnopleuric layer of the pericardial sac and the viscernal layer of the pericardium is also formed from the same splanchnopleuric layer.

Pericardium is the Kala based on these three things. It can be said for sure and it will be clear which of these seven Kalas it is by considering the description of these seven Kalas. 1. Kala: The second Kala is called bloodstream. It is present in the Mansa, especially in the veins, and in the liver and spleen. Just as the milk comes out by hitting the milk tree, the blood comes out of the Mansdhatu immediately by hitting the Mansdhatu. Sira, liver and spleen are mentioned in the special place SirasuYakrataplihoshch (Sushruta) especially Siraplihayakrutsu (Ashtanga Sangraha $)^{(14) .}$ The vein here refers to the blood vessel i.e. the artery and the vein. Yakrutplihosch - The reason these two organs are specially mentioned is their connection with hematology. Another reason is that these 
organs have more blood than other organs in the body. That is, these organs are the reservoirs of blood. Now, from the description of Kala, it can be seen that Pericardium does not fit anywhere here because the heart or Pericardium is not mentioned in the special features of Kala. The pericardium does not contain actual blood Dhatu, it contains arteries and veins. But since they are small, it cannot be called Kala Kala.

MedodharaKala: The third is the Kala called Medodhara. Fat is found in the abdomen and small bones of all animals, and in large bones. It is especially fun to shelter in the middle of large bones and in all other (small) bones (whatever is fat) is called Sarakt Meda. The Sneha of pure Mansa is called Vasa.

Abdominal -: There is always a modest accumulation of fat in the human body. This accumulation increases when a person becomes sthul. As the fat is more concentrated in each part of the obese person, however, more of it is in the abdomen, buttocks and breast region.

Throughout the body, this accumulation is mostly in the subcutancus tissue. In addition to this location in the abdomen, fat accumulates in one Kala of the abdominal cavity. This Kala carries Vapa (fat) so it is called Peritoneum. According to Chakrapanidatta, due to the highest accumulation of fat in the abdomen, the abdomen is mentioned here. Meda, Majja and Vasa - Twelfth verse have been shown to distinguish between them. In the human body, in the bone marrow, under the skin and in peritoneum.

It is present in the Mansa and in the abdomen. There are two distinctions of the Majja, one is the Pitta Maj$j a$ and the other is the Rakta Majja. This marrow is yellow so the marrow should be called Yellow Marrow. The small bone contains red Majja, so the red plain should be understood as Red Marrow. Fat is the sneha of pure Mansa. So, vasa should be understood from fat content of flesh. Now the fat that is left can be absorbed and the fat under the skin can be removed. Chemically, fats and oils are in the form of pure fats. Yellow dies are high in fat and red fat or red marrow is low in parietal aphids. Ayurveda has fourfold Sneha-Sarpi, Tailam, Vasa, and Maj- jasneha ${ }^{(15)}$. It does not mention fat, so it is included in the fat. Here the connection between the abdominal fat and the inner fat in the small bone is not good, the abdominal fat is pure fat. And the small bone marrow contains very little fat and the red blood cells that it produces are erythroblasts, which cause redness. In a way, the name given to the fat by people is correct in one sense. From this it appears that the Medodhara Kala is found only in certain places and that the pericardium does not contain any medulla, so the pericardium cannot be considered as Medodhara Kala.

Shleshmadhara Kala: The fourth is the Kala called Shleshmadhara Kala, which is present in all the joints of the animal, just as the chakra rotates properly by applying oil on the axis, so the joints move smoothly. Applying oil on the axis reduces the noise in the wheel, reduces the friction between the axis and the wheel, rubs the axis, works for a longer period of time i.e. for its entire life and takes less effort to pull the vehicle and the vehicle runs faster. The mucus from the mucous membrane is absorbed into the inner body of the joint, so there is no noise, no friction, no heat, the body rubs less, the joints work longer. They take less effort to bend and the animal can move or act faster. Consistency: There are three types of joints (Sandhi) in the body. 1. Static / immovable and 2. moveable 3 slightly moveable - who are stable do not have speed so all joints should be considered in all joints. When the synovial joint cavity is opened, a capsule is found in it. A thin shiny layer remains on its inner surface (Synovial Membrane). A synovial fluid comes out from this layer. In the machine or in the chakra that makes Vangan [Lubricant]. Thus, it becomes clear that the mucous membrane is at the point of variability and no variability is found at the site of the pericardium.

Although the pericardial fluid is spontaneous, it does not benefit any circulatory system. It benefits the contraction and dilation of the heart, so the pericardium cannot be a mucous membrane

Purishadhara Kala: This is the fifth Kala which separates the mala located in the duodenum in the chamber. The fecal membrane, which is contained in the intestine adjacent to the liver and constipation, sepa- 
rates the mala from the intestine. Intestine - This can be understood as both large and small. However, since the work of defecation is done only in the Large, 'Antrani' should be understood as large. Digestion of food consumed by mouth and absorption of satmyabhaga takes place in Sadantra. As long as Satmyabhaga and Malbhaga live together, that fluid cannot be called Mala. By the end of the small intestine, almost all the ansh of the satmyabhaga are absorbed, and in a state where only feces and water are present in the large intestine, the function of the large intestine is to absorb only the fecal water. If the stool reaches the anus in a timely manner from the onset of large intestine, $80 \%$ of the water is absorbed. If the stool stays in the intestines for a long time due to constipation, it absorbs more water and the stool becomes hard and lumps form. In a nutshell, the faeces that reach the large intestine are separated by water, and this is done through the interstitial space of the gland. From this it is certain that the Purishadhara Kala is in the place of large intestine and it divides mala and Pericardium does not divide any mala and its place is in Ura so Pericardium cannot be called Purishadhara Kala.

PittadharaKala: which holds four types of annapana which are useful for passing from stomach to duodenum. The unhealthy, edible, yellow and lead food that reach the human intestine are degraded in due time due to the bile. Digestion - The action of the digestive juices, the process of digestion of the consumed substance in many molecules, is called digestion. It is clear that the limit of bile is from stomach to duodenum. Bile duct means duodenum. It was only after this that the limits of Purishadhara Kala began. From this it is clear that the bile duct digests and absorbs food and it is duodenum and Pericardium does not digest and absorb any food and it is above the stomach and not between the stomach and duodenum so Pericardium will not be the Pittadhara Kala.

Shukrahdara Kala: It pervades the whole body of all animals. Just as (whole) milk contains ghee and sugarcane juice contains jaggery, likewise, the human body contains Shukra. Two fingers below the basti (bladder) door in the right and left foot (accumulated in the located spermatozoa) the male sperm comes out (through) the urinary tract. The omnipresent Shukra of the (Purusha) which is pleased with the mind and Strisang is thrown out due to Harsha (Shukradhara Kala). In order to easily prove the omnipresence of Shukra described in the 19th Sutra, the omnipresence of Shukra is described with an example in the first verse. But in view of its practical uselessness, the omnipresence of Shukra is described with an example in the first verse to easily prove the omnipresence of Shukra in other people. But seeing its practical uselessness, the second verse gives its actual position and the way out of Shukra, and the third verse gives the reasons for Shukra to come out. The posterior of the bladder contains two sac and two systems. There is a system on the inside of the bag. The bag is called Vesiculoe Seminalis and the system is called Vas Deferens. The end of the spermatic system is in the lower. Where the testicles and spermatozoa meet, a tube begins. This tube is called the ejaculatory duct. This description shows that the pericardium has nothing to do with spermatogenesis. This proves that the Pericardium does not bear any resemblance to these six $\mathrm{Kal}$ $a$ s. Let us now look at the description of the Mansadhara Kala.

Mansadhara Kala: It is the first Kala. The fleshy flesh that contains the branches of the sira, snayu, dhamani, srotas. Just as the fibers of the lotus in the muddy water spread all over the land, so the sira spreads in the mansa, the description of Mansadhara Kala is very similar to the pericardium. Mansadhara Kala is the Kala of holding Mansa (Dhatu). The pericardium also holds the heart muscle. The pericardium also has a network of branches of internal thoracic Artery descending thoracic aorta, coronary arteries, branches of azygos and internal thoracic veins, phrenic nerves, vagus \& sympathetic nerves. The fact that there is no specific place for this Kala of Mansa means that the Kala must be in the place where the Mansa is, otherwise like the other six Kalas, its special place would have been mentioned by Sushrutacharya ${ }^{(16)}$.

Musculoskeletal blood vessels: Kala is compared to the lotus and for the explanation of the Mansadhara 
Kala also the Mansadhara Kala is compared to the lotus. There are many similarities between the two. Considering all these, Pericardium is Kala and its close connection with the heart is made of Mansa, so its connection with the Mansa is clear from the above points. So Pericardium can be included in the Kala of Mansadhara Kala.

\section{CONCLUSION}

The following conclusions are drawn from the study of Ayurved and Modern texts, dissection and actual body in the context of the Kala and Pericardium.

1. Kala is a gross organ up to certain extent.

2. The Kala are the nervous, intestinal, and mucous membranes, meaning they belong to the Fibrous, Serous, or Mucous Membrane.

3. The number of main Kalas is only seven.

4. Along with the Dharan of Kala, there are other functions that can vary according to the Kala; thus, Kala has special qualities.

5. Charak, Sushruta, Vagbhata have not described any special Kala.

6. Pericardium is very similar to Mansadhara Kala, so it seems reasonable to include it in Mansadhara Kala.

Ayurvedic and modern medical knowledge is like an endless ocean. This study done in research on this subject is similar to the bowl picked up for Ramsetu. Therefore there is still a great need for research in this field.

\section{REFERENCES}

1. Sushruta Samhita Dalhan Tika Trivikramatmajen Yadavsharmana Chaukhamba Sanskrit Sansthan Varanasi, Page no 355, page no 364.

2. Vd. Jadaoji Trikamji Acharya, CharakSamhita, ChoukhambaPrakashan, Edition Reprint 2009 Varanasi, Sharirsthan 8/51, Page no. 350.

3. Ashtanga Sangrah - Kaviraj Atridev Gupta Chokhambha Prakashan, Varanasi page no 113

4. Sushruta Samhita Kaviraj Dr. Ambikadatta Shastri Chaukhambha Prakashan, Varanasi Su.Sha. 4/31

5. Sushruta Samhita Dalhan Tika Acharya Yadavji Trikamji Krishnadas Academy, Varanasi Su.Sha. 5/11
6. Dev Raja Radhakant, Shabdakalpadrum, Nag Publications,Delhi, page no 56.

7. Dr. Bhaskar Govind Ghanekar, Shushrut Samhita, Sharirsthan, 4/27, Publication M.L. New Delhi, Reprint 1995, Page No.117

8. Sushruta Samhita DalhanTika Trivikramatmajen Yadavsharmana Chaukhamba Sanskrit Sansthan Varanasi. Page no 355.

9. Charak Samhita Chakrapani Tika Shri Narendnath Sen Gupta Chokhambha Sanskrut Prakashan, Varanasi.

10. Rojer Worwick \& Peter William, Gray's anatomy, E.I.B.S. Publications

11. Dr. Bhaskar Govind Ghanekar, Shushrut Samhita, Sharirsthan, 5/14, Publication M.L. New Delhi, Reprint 1995, Page No.111

12. Ashtanga Hriday Pt. Kashinath Shastri Shri Vaidyanath Ayurveda Bhavan Nagpur.

13. Bhavmishra, Bhavmishra Samhita, Madhyam Khand, Commentary, Varanasi, Chaukhamba Prakashan, Reprint 2012.

14. Dr. Tripathi Bramhananda, Ashtang sangrah, Nirmala Hindi, Commentary, Delhi, Chaukhamba Sanskrit Pratishthan, Reprint 2015.

15. Dr. Tripathi Bramhananda, Charak Samhita, Poorvardha, Varanasi, Chaukhamba Subharati Prakashan, Edition2015, Chapter 11, page No. 216

16. Sushruta Samhita Pandit Bhaskar Govind Ghanekar Meharch and Prakashan, New Delhi,page no 108,109.

\section{Source of Support: Nil Conflict of Interest: None Declared}

How to cite this URL: S Sumedha Y. Kotangale et al: Study Of Pericardium With Special Reference To 'Kala Sharir'. International Ayurvedic Medical Journal \{online\} 2020 \{cited July, 2020 $\quad$ Available from: http://www.iamj.in/posts/images/upload/3982 3988.pdf 